\title{
Impact of Displacement Phenomena on Landscape Identity: Application of Cultural Values Model
}

\section{Ali Ashraf Mohamed Talat lbrahim*, Jūratė Kamičaitytė}

Kaunas University of Technology, Faculty of Civil Engineering and Architecture,

Studentu st. 48, LT-51367 Kaunas, Lithuania

*Corresponding author: ashraf.ali@ktu.edu

Гrossuref $h$ htp://dx.doi.org/10.5755/j01.sace.28.1.27675,

The research attempted to discover the impact of displacement phenomena on the identity of landscape, by using Janet Stephenson's Cultural Values Model to study and analyze cultural landscapes. The model was chosen due to its universality, simplicity and embodiment of the relational concept of landscape perception and evaluation. The result of landscape evaluation depends on the characteristics of both landscape and observer, as well as on the relation of the object and subject. In order to understand the complexity and diversity of landscape and its identity, these were analyzed through a ternary system, consisting of forms, practices, and relationships, i.e. what is seen, what is happening and what it means to those who see and use it. The research represents a feasible and pragmatic approach to understand the complexity of landscape and its identity, by tracing back their retrospective changes due to the impact of displacement phenomena - a shift of objects, behaviours or relationships. Through this theoretical and methodological model, multiple universal correlational patterns were developing, in which the three components encountering the displacement behave and interact with each other, leading to an ambiguous impact on landscape identity and the socio-cultural quality of the human living environment. By studying and time-tracking different landscape cases that experienced major displacements from around the world to one of landscape's systemic components, the research results show some regular patterns in landscape identity changes, and how its structural tangible and intangible system performs and effects in creating, or destroying landscape identity, defying the limits of spatial and historical context.

Keywords: displacement phenomena, cultural values model, landscape, identity.

The term "Landscape" is comprised of everything that is perceived, making the term an extremely broad one, but that is also frequently associated with only the natural elements of our environment. (European Landscape Convention, 2000) defines landscape as an essential component of people's surroundings, an expression of the diversity of their shared cultural and natural heritage, and a foundation of their identity.

Any landscape that is used by humans is inclined to get influenced by man-made objects and the intangible subjective aspects of the human perception, transforming it into "Cultural Landscape", whereby an interplay connection between the tangible and the subjective aspects of landscape occurs (Triandis, 2000).

To control this wide-ranging elements of landscape, Dr. Janet Stephenson's Cultural Values Model (2007) was used as a blueprint for identifying landscape and their elements. Selection of the Cultural Values Model of Stephenson was based on its simplicity, comprehensiveness and its preci-

\section{Introduction}

Impact of Displacement Phenomena on Landscape Identity: Application of Cultural Values Model

Received 2020/09/17

Accepted after revision 2020/11/10

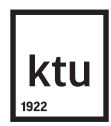

Journal of Sustainable Architecture and Civil Engineering Vol. 1 / No. 28 / 2021

pp. $5-14$

DOI 10.5755/j01.sace.28.1.27675 
sion in modeling cultural landscape. The model works by categorizing and blending both material objects of nature and man, their subjective aspects, and considering the physiological, and psychological experience when utilizing, and perceiving landscape. The Cultural Values Model made it possible to study and analyze landscape in a ternary view, dividing it into: 1) forms - all visible elements, natural and man-made (man-made elements are divided into two main subcategories: 1A) Forms of Figures, sculptural or monumental forms, and 1B) Forms of Practices, forms that can host functions, architectural buildings), 2) practices - all types of behaviours and functions that occurs, and 3) relationships - all that is the collectively agreed subjective aspects, and their significance. In addition, Stephenson took into account the temporality of landscape in the Model, since time was perceived as having a role in shaping the identity of the landscape. Therefore, the current visible and perceivable landscape is a result of the present layers and all the past layers that are either evolved or overwritten by the present layers as the landscape will always maintain a residue attachment to the past layers.

The research attempts to explore the development of landscape layers, identify their elements connections, and how they interact with each other, to fill the gaps of knowledge regarding cultural landscape's behaviour; to find the answers to the questions if there is a specific dynamic those three elements communicate, and is there a language, pattern or sequence of landscape's identity and how it behaves due to the occurrence of displacement phenomena - a shift of forms, practices (functions) or relationships.

The chosen research method is a case study. Case studies were selected based on their capacity to unveil previous embedded layers of landscape, and how these affected landscape's identity when it was visible. Selection of cases started from selecting cases that had major displacements. For example, Ramses Square in Cairo was named after Ramses II statue that got displaced to the new Egyptian museum but maintained its name. Similarly, to the displaced Ancient Egyptian object, the other selected case was Place de le Concorde in France, where one of the obelisks from Luxor Temple was displaced to the busiest square in Paris. The displaced objects and their influence led us to study local case with similar situation like Grutas Park in Lithuania and study the impact of removing Soviet sculptures from the city to natural green area in altering landscape's identity.

The aim of these cases analysis was to allow us to study and understand the impact of displacement of one of the landscape components (forms, practices, and relationships) on the other two, which led to the selection of three cases of major displacement per each component, leading to a selection of nine initial cases. For the analysis of displacement of forms Ramses Square in Cairo Egypt, Grutas Park in Lithuania and Marble Arch in London were selected. For the analysis of displacement of practices Wynwood Walls in Miami, United States (selected due to the displacement of warehouses to art spaces, which led to economic development of the area), Frida Kahlo Museum in Mexico (changed from a private residential house to a museum), and provisional capital Kaunas in Lithuania, experimenting historical tracing to city scale, were selected. And finally, for the representation of relationships displacement, cases of uprising and revolutions were selected such as Pearl Roundabout in Bahrain, Place de la Concorde in Paris, and the case of Luxor Temple where four different religions existed in the same structural complex.

The interconnection of objects history and their displacement from or to different context, required us to study these connections universally and not contextually. From this sequence of selections, we managed to obtain universal language and behaviour of landscape identities from around the world, ranging from America, Africa, Europe and Asia.

Overall, the research method was divided into five steps: collecting historical data (1), analyzing the data through event timelines (2), transferring the data to displacement tables (3), creating landscape identity tracking system readings (4), and labelling landscape tracking systems (5). 
Detailed historical data about the studied objects were collected from multiple resources. The objects could either be for example an urban area, or a singular building. Then the data were filtered and narrowed to the three elements of landscape identity: forms, practices, and relationships.

Historical data is the main determiner of landscape identity readings: the more informative and granular they are, the more accurate the resultant readings will be. The most important historical data that should have been gathered in the context of this research were the changes that occurred to one of the three studied elements (forms, practices, or relationships), and if possible, their impact on each other.

It should be noted that the elements of forms and practices are relatively easy to trace, since the former is related to the physical changes of the studied object, the latter is related to the change in the object's functions. In general, both elements are more readily available in the historical archives. As for the element of relationships, this has been derived by either how the society identified or named the studied object, or by utilizing other manifest indicators, such as news of vandalism or 'controversial' reactions.

Below there is a case example of how three elements evolved and interacted over the time at Ramses Square (Fig. 1). There were several pivotal changes that impacted the studied area, most notably:

_ The development of the area from a village named "Um Danin" to Cairo's main railway station, by building the station and officially changing the name of the area to "Bab Al Hadid" (The Iron Gate).

The placement of Nahdet Misr statue in a central location within the square, an event that created an additional relationship by referencing the square as Nahdet Misr Square.

The displacement of Nahdet Misr statue from the square to Giza, and then its replacement with the Ancient Egyptian statue of Ramses II, an event that led to changing the name of both the square and the railway station to Ramses Square and Ramses Station

The displacement of Ramses II statue to the Grand Egyptian Museum site in 2006. Unlike the previous displacement, the square and the train station maintained their name which referenced the displaced statue.

To simplify the historical data, an event timeline was created (Fig. 2) that indicates the displacement of each one of the landscape elements, and shows their influence on each other. The event timeline allows us to indicate missing information from the collected data, and whether it is necessary to find them or not. Accuracy of sudden impact of one element on the other is not necessary, as the displacement of one element can influence the other two months, or few years later, or not at all.
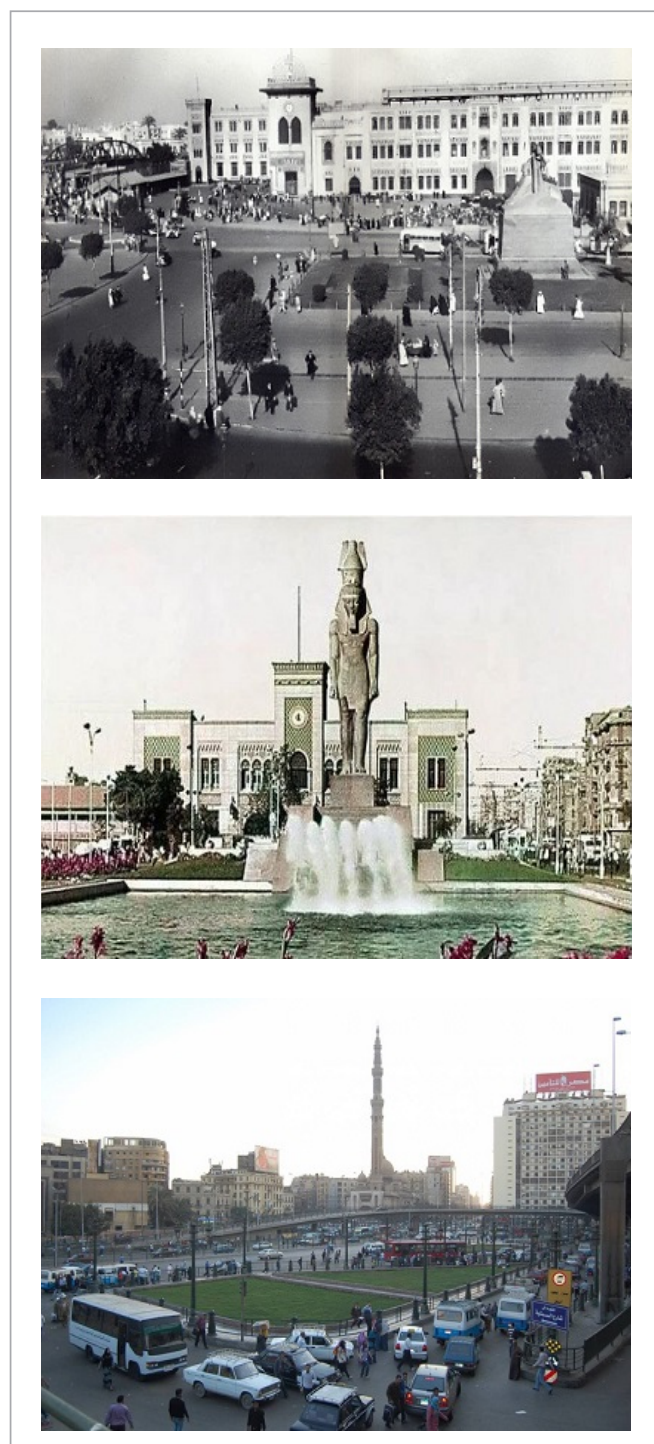

Fig. 1

The evolution of Ramses Square (from left to right): Nahdet Misr Square, Ramses Square with Ramses II Statue, Ramses Square without the statue (Electronic Portal of Cairo Governorate) 
Fig. 2

The event timeline of Ramses Square

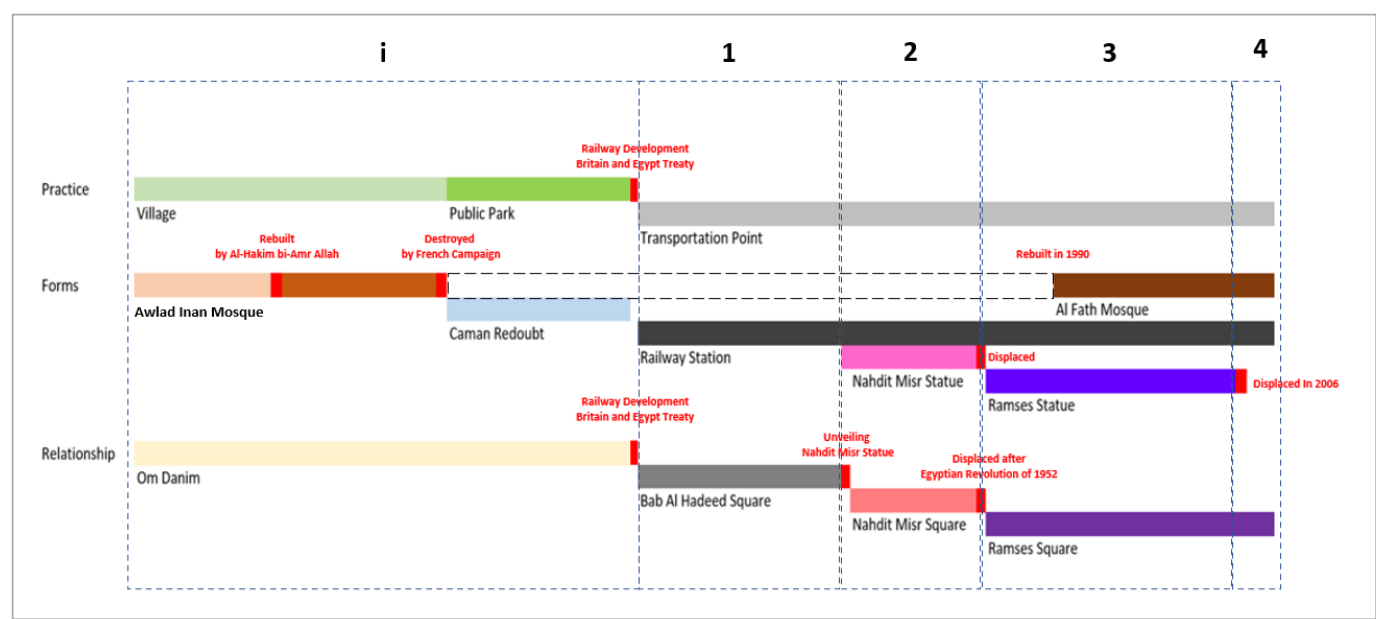

Developing an event timeline starts with the process of dividing historical data to the three components. By mapping them out linearly, it allows us to see if there was an impact in the displacement or not. In the initial state, we can see displacement of forms occurring but not affecting either practices or relationships (Fig. 2). Effective displacement started when there was a shift in more than one of the components, in this case all three components, and that was after the area became Cairo's main transportation point. Second and third displacements were between the forms and relationships, while the practices remained stable.

A displacement table was then created in order to highlight further the displacement events and their impact, thus showing the number of displacements and how they affected each element of landscape, beginning from the initial studied state to the current state (Fig. 3).

Fig. 3

Example of a displacement table (the case of Ramses Square)

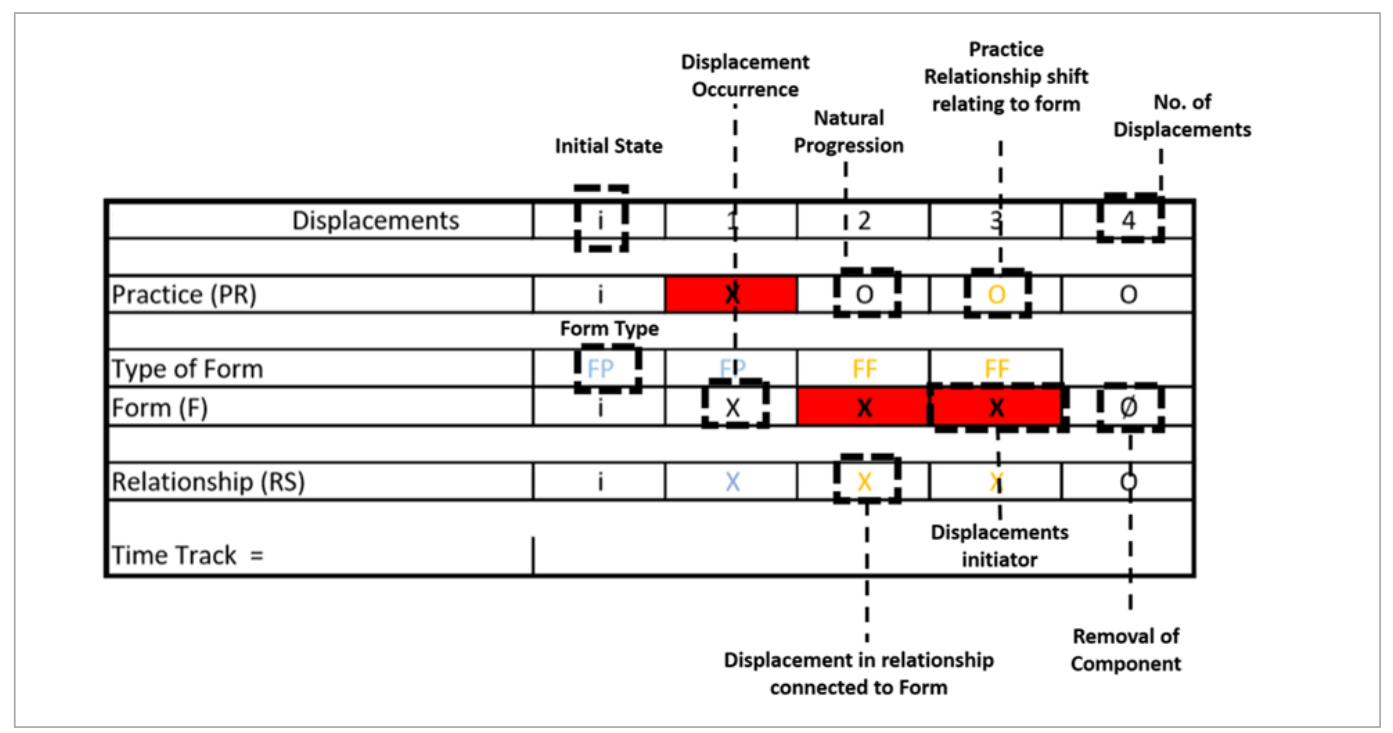

The red label indicates the initiator of displacement. In the case of Ramses Square, by changing the main practice of the area from the village to transportation point, one can ask: did the occurrence change the physical features of the square? If yes, then forms get an $\mathrm{X}$, if no, it can be indicated with 0 . The same can be applied to the forms and relationships. The safest way to indicate relationships and their displacement is according to the name of the square: did it change how people identify and perceive the building? If yes, then relationships get an $X$, if no, it is indi- 
cated with $0 . \varnothing$ indicates the absence or removal of the preceding component. For ex., in Ramses Square the form of figure is no longer there, so it was indicated with the symbol $\emptyset$.

From the studied cases, there was an evident difference between sculptural forms (ones that do not host functions), and functional forms (buildings that host functions), which were separated to forms of figures (FF) and forms of practices (FP).

Later each initiated displacement and its influence was demonstrated by creating a model of landscape identity system. Through it we can see the communications and sequences in visible readings (creating landscape identity tracking system readings), and by labelling them we can analyze and study them quantitively (Fig. 4).

Selection of forms of practices or forms of figures depends on the current stage of timeline that is being studied: if the form of figure (statute or monument) or the form of practice (building) is changing the landscape identity.

The red indicates the initiator, the arrow indicates the sequence of impact, starting from the initiator, according to the data of displacement table. All readings indicate the displacements that occurred to the studied objects. Displacement readings that have the same figure are labelled with a letter. Reading that precedes with letter $\mathrm{R}$, indicates "Result", showcasing situation pre- or post-displacement. R1 in the example (Fig. 5) indicates the absence of form of figure, while R5 indicates presence of all three elements, representing the current state of the building.
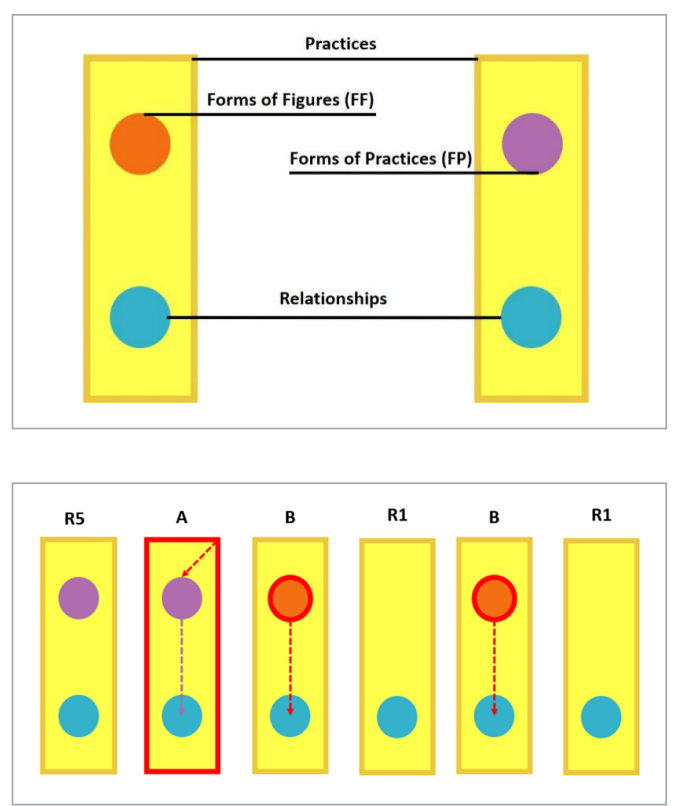

The labelling is a final stage by captioning the historical events of displacement readings, and the results that occurred in the studied objects. All the collected data are summarized and represented in one detailed diagram (Fig. 6).

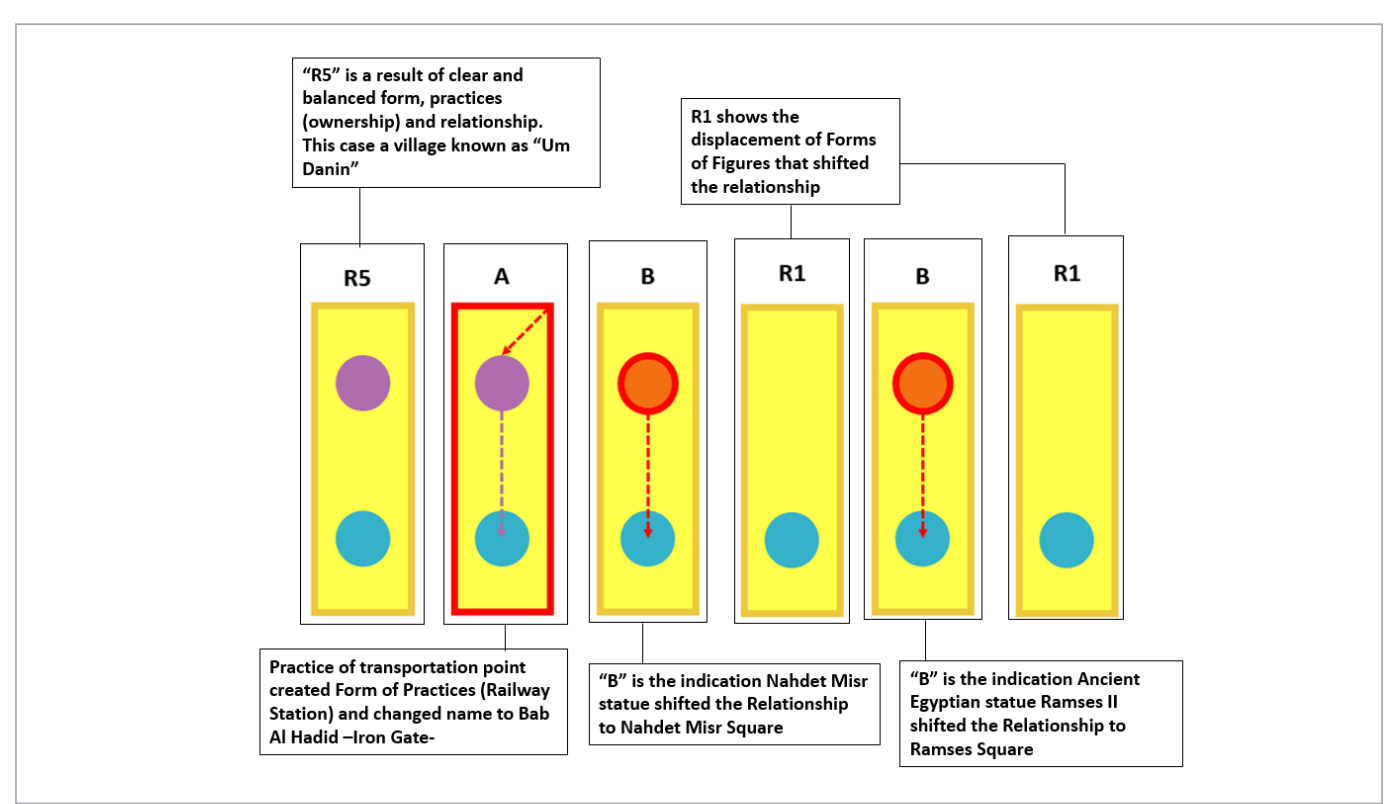

Fig. 4

Diagram of reading Landscape Identity Tracking System

\section{Fig. 5}

The example of landscape identity tracking model (the case of Ramses Square): yellow colour represents practices, blue - relationships, violet forms of practices, orange - forms of figures

\section{Fig. 6}

The example of landscape identity tracking model (the case of Ramses Square): yellow colour represents practices, blue - relationships, violet - forms of practices, orange - forms of figures 
The method outlined above, which has been undertaken on each of the nine case studies, made it possible to understand how the main elements of landscape have developed or changed throughout time.

\section{Results}

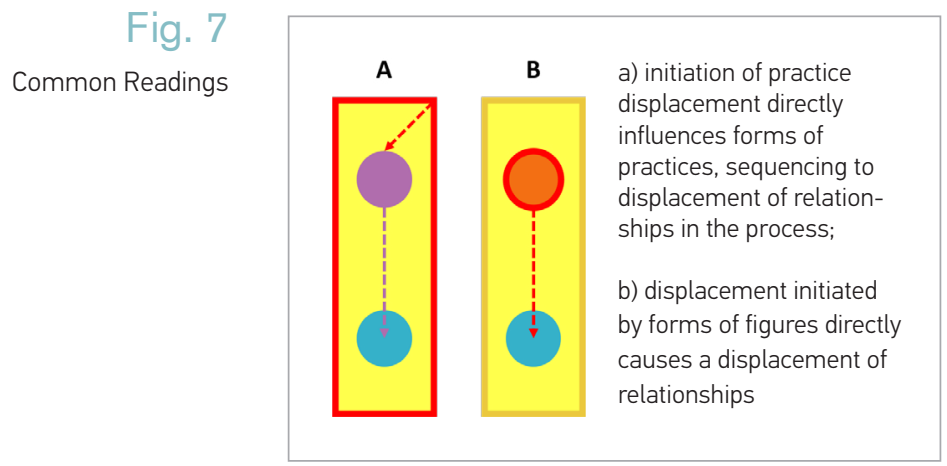

It was seen in the cases of the statues of Ramses and Nahdet Misr in Ramses Square, where they both changed the name of the area in relation to them. Even the displacement of Nahdet Misr statue to another square in Giza changed the name of its street to Nahdet Misr. Statue of Louis XV determined the previous name of Place de la Concorde in Paris, Marble Arch in London, Pearl Monument in Pearl roundabout Bahrain, Stalin sculptures in Grutas Park also known as Stalin Park. Equal common reading was the displacement initiated by practices to

Forms of Practices (Fig. 7a), that consequently changed the relationships. The railway station created the relationship of Bab Al Hadid (the previous name of Ramses Square), public execution space changed Tyburnia to Tyburn Tree (previous name of Marble Arch) relating to the gallows. The warehouse of Wynwood after displacement to art galleries, changed the use of the area from lower income residents to high income users, ultimately leading to the gentrification of the area.

By comparing the impact of 'forms of practices' and 'forms of figures' to the landscape identity, through creating the association - naming of landscape, the analysis results showed that non-functional forms (forms of figures) had higher influence than functional buildings (forms of practices) (Fig. 7) on the landscape identity. 33\% of the cases had 'forms of practices' relating landscape to them, $22 \%$ of them were displaced after introducing form of figure to the landscape, $55 \%$ of the cases had landscape identity associated to their 'forms of figures', and only 22\% were displaced after their destruction due relationship displacement.

The previous statement proves that relationships remain the most impactful and influential element on landscape identity, their displacement can disrupt the stability of the landscape, which can cause revival or erasure of the visible elements of landscape.

From all nine studied cases, we were able to indicate conditions of stability and instability of landscape identity. Different but complimenting relationships do not disturb stability of landscape identity, nor singular relationships. As it was seen in Frida Kahlo Museum case, which is known as The Blue House to most locals and as Frida Kahlo's House to tourists, or Grutas Park and Stalin Park. The conflicting relationships in one society to a singular visible form cause the instability of landscape identity. It shows the case of Bahrain's Pearl Roundabout, where a monument that symbolizes the unity of the five gulf countries was displaced to a symbol of the 2011 uprising, which led to the decision to destroy it by the government. In Place de la Concorde, previously placed statue of Louis XV was destroyed by French revolutionists, making it the square where the execution of the monarch family took place. 
The results of the readings of the Landscape Identity Tracking System varied a lot due to the different historical events that took place in each case. However, $100 \%$ of the cases that had displacement initiated by relationships when 'forms of figures' were present, caused their destruction, occurring in $22 \%$ of total cases (Fig. 8) despite their historical and contextual differences.

Displacement of relationships due to the political systems and collective reactions, transformed public squares into a space of uprising, leading to the destruction of main forms of figures (Fig. 8). In Louis XV square, currently known as Place de la Concorde (Fig. 9), the sculpture was destroyed by rebels, and in Bahrain Pearl Roundabout the government destroyed the monumental form that became a symbol for the protestors after the exhaustion of the uprising (Fig. 10). Both uprisings had different conditions and results, but ultimately both symbolic forms were razed. In addition, the names of both areas changed, Louis XV to Place de la Concorde, and Pearl Roundabout to Al Farooq Junction (Fig. 10). When compared to the removal of Ramses II statue in Cairo, which was displaced due to being threatened by pollution and the shaking of the underground metro beneath, the name of Ramses Square retained. This indicates the different displacement of forms of figures that is initiated by shift of relationship in comparison to one that is initiated by practice.

Difference between the impact of conflicted relationships on 'forms of practices' and 'forms of figures', shows that 'forms of figures' are more subjected to get destroyed and displaced (Fig. 11). It can be explained by the purpose of 'forms of figures' as being a symbol of glorification and an objective representation of intangible aspects of societies or governments in landscape. Conflicted relationships to 'forms of practices' could possibly lead to their destruction, but the possibility of adaptation and reusing of these structures to the public purpose allows over-
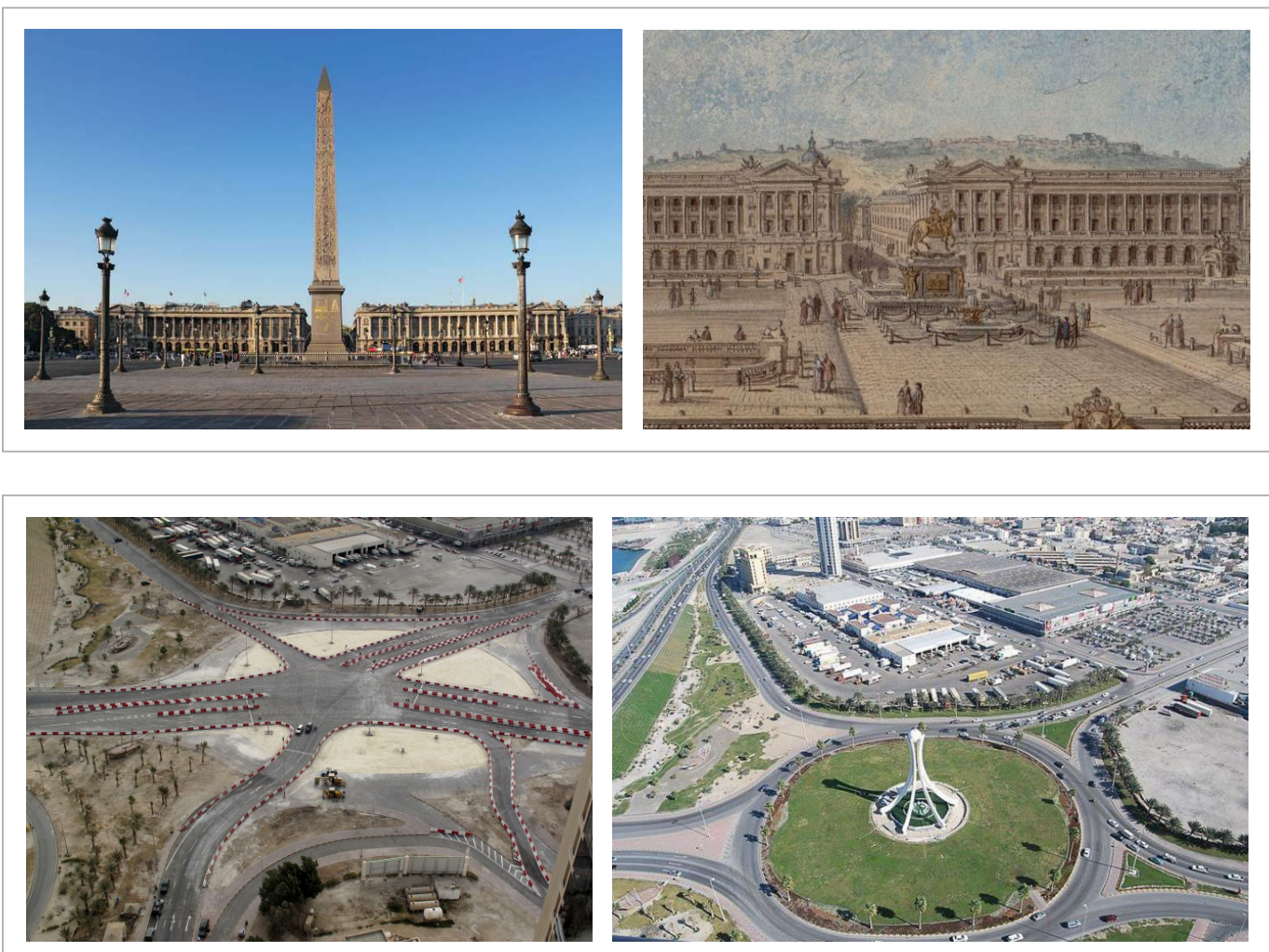

Fig. 8

Repeated pattern $\mathrm{G}$ with displacement initiated by relationships causes danger to forms of figures, resulting in their displacement or destruction

Fig. 9

Place de la Concorde (Paris, France): present features with Luxor Obelisk in center (left) (photograph: ArTo/ Fotolia), Louis XV sculpture before the French revolution painted by Nicolas Pérignon (1780) (right)

Fig. 10

Displacement case of Pearl Roundabout: Al Farooq Junction after the destruction of the pearl monument in 2011 (left) (photographed by Lewa'a Alnasr), Pearl Roundabout prior to the destruction (right) (Photographed 2010 by Sheyma Buali) 


\section{Fig. 11}

Forms of practices vs. forms of figures with conflicted relationship subjecting forms of figures to be destroyed and displaced

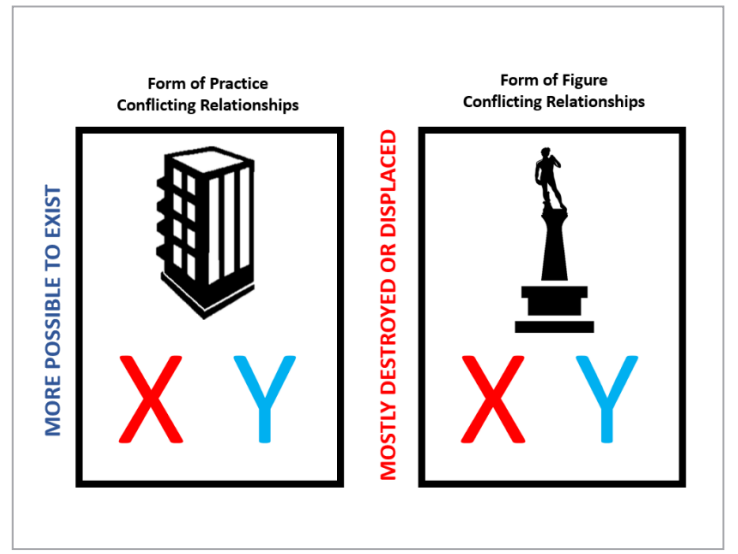

coming such conflicts, that is something 'forms of figures' cannot possibly do, due to their inability of hosting functions.

Destruction and displacement of 'forms of figures' is a phenomenon that repeatedly occurred throughout history, due to the rise of conflict towards the symbols they represent, like the toppling of Saddam Hussein Statue in Iraq in 2003, Louis XV during the French Revolution, and it is currently being witnessed with the most recent development of the Black Lives Matter Movement in 2020, against sculptures of colonial figures and slave traders across confederate states in America. For example, toppling statues of Robert E. Lee and Jefferson Dennis, in Belgium statues of Leopold II were vandalized and displaced, in United Kingdom statues of Edward Colston got toppled by protestors, and statue of Robert Milligan that was officially removed (Fig. 12), and more countries that are taking the procedures of removing colonial statues safely, including New Zealand and Greenland.

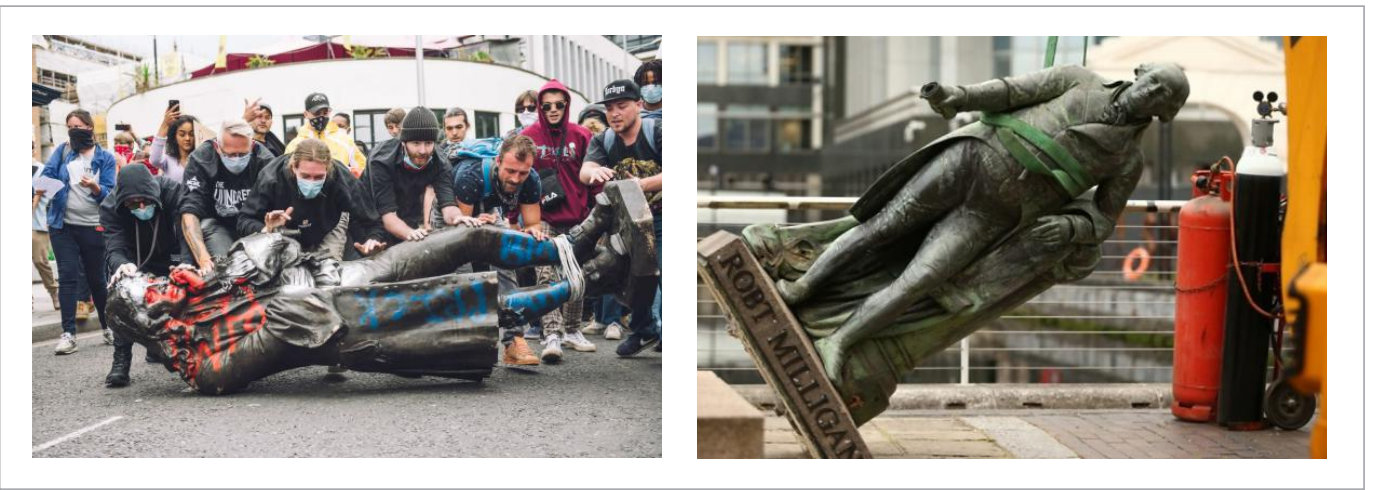

Landscape and its identity can be understood and studied through J. Stephenson Cultural Values Model using three main elements of Forms, Practices (functions) and Relationships. In our research we proposed to develop it in order to observe the communication and behaviour each element conducts with the other, and what impact it has to user's perception.

Visible landscape consists of two categories: Forms of Figures and Forms of Practices. Forms of Figures are non-functional symbolic forms (sculptural or monumental) representing intangible history of the place, and Forms of Practices are visible structures (buildings) that host functions and make the built environment of landscape.

Forms of Figures help sustaining and manifesting relationships, and Forms of Practices sustain daily economic and social life. Each differing on the way they influence the identity of landscape, and 
the challenges they face in the occurrence of conflicted perception. Symbolic weight and controllable size of Forms of Figures highly subjects it to the destruction or displacement.

Creation of the landscape identity tracking system created the possibility of transforming unique historical events into a readable uniform figure - pattern, providing readable diagrams. It allows us to indicate the missing elements that detain effective visual identity of landscape, creating a different approach to design solutions through two possible methods: one is by creating relationships out of the existing visible elements, or constructing visible elements out of the existing relationships that are not currently anchored by the visible environment.

The landscape identity tracking system can also allow us to compare other cases of displacement that occur during political and social shifts. The historical events and displacement sequences have similar progression and results, irrelevant to historical and spatial context, possibly allowing us to predict outcomes when these similar events re-occur in different places. The development of research in the future could be aimed at finding an explanation and deeper understanding of impact of different types of displacement phenomena on landscape, that results in cultural amnesia, cultural erasure, multiculturalism, gentrification, or urban segregation.

First and foremost, I would like to thank Jūrate Kamičaityte for her interest and insightful input in conducting this research for my master's study. Indre Grazuleviciute-Vileniske who guided me to J. Stephenson Cultural Values Model that eventually became the main blueprint to the research. Kęstutis Zaleckis, who's step-by-step guidance and input helped creating the content and find the direction to the research. And lastly, Elizabeth Eden Harris, who's words and creativity motivated to continue the research productively.

ArTo/Fotolia. (2019, December 11). The Luxor Obelisk on the Place de la Concorde, Paris. [Digital image]. Retrieved June 1, 2020, from https://www.britannica.com/place/Place-de-la-Concorde

Buali, S. (2013, February 28). Pearl Roundabout [Pearl Roundabout in 2010]. Retrieved June 17, 2020, from https://www.ibraaz.org/essays/56

European Landscape Convention. European Treaty Series, 2000, (176), 1-7

Mok, Y./ PA Images via Getty Images (2020, June 10). Removal of Robert Milligan statue [Workers prepare to take down a statue of slave owner Robert Milligan in London.]. Retrieved July 1, 2020, from https:// news.artnet.com/art-world/monuments-uk-belgium-1883412

PA Images, NurPhotos. (2020, June 08). Protesters transporting the statue of Colston towards the river Avo [Edward Colston statue being toppled]. Retrieved July 1, 2020, from https://www.mirror.co.uk/ news/uk-news/darren-lewis-edward-colston-statReferences ue-22155008

Pérignon, N. (1780). Vue de la place Louis XV, avant la construction du Pont [Painting]. Retrieved November 17, 2020, from http://peccadille.net/2014/05/09/ avant-la-concorde-et-lobelisque-la-place-louis-xv/ Photograph found in Ramses Square Cairo. (2020, March 02). Retrieved June 1, 2020, from http://www. cairo.gov.eg/ar/Bank\%20of\%20ldeas/Pages/ashhur-mayadin-alqahr-text.aspx?ID=10

Stephenson, J. Many Perceptions, One Landscape. Landscape Review, 2007, 11(2), 9-30.

Stephenson, J. The Cultural Values Model: An integrated approach to values in landscapes. Landscape and Urban Planning, 2008, 84(2), 127-139. https://doi. org/10.1016/j.landurbplan.2007.07.003

Triandis, H. C. (2002). Subjective Culture. Online Readings in Psychology and Culture, 2(2). https://doi. org/10.9707/2307-0919.1021

\section{Acknow- ledgment}




\section{About the \\ Author ASHRAF MOHAMED \\ TALAT IBRAHIM ALI}

\section{Masters Student}

Kaunas University of Technology, Faculty of Civil Engineering and Architecture

\section{Main research area}

Displacement, culture and Identity

\section{Address}

Taikos Pr. 34-43

Tel. +37062266113

E-mail: ashraf.ali@ktu.lt

\section{JŪRATE் \\ KAMIČAITYTÉ}

Professor

Kaunas University of Technology, Faculty of Civil Engineering and Architecture

\section{Main research area}

Landscape visual quality analysis, evaluation and regulation, methods of planned activity or object visual impact assessment, analysis of social preferences evaluating landscape visual quality and use of the analysis results in territory planning, evaluation of the potential and dynamics of urban structures, cityscape identity studies, expression of sustainable development conception in architecture, landscape architecture, town and territory planning.

\section{Address}

Studentu st. 48, LT-51367 Kaunas, Lithuania Tel. +37061477082

E-mail: jurate.kamicaityte@ktu.lt 